\title{
La corrupción como delito en el pensamiento del siglo XIX. Un esbozo de su conformación jurídico-penal en la historia desde la filosofía
}

\author{
The Corruption as Crime in the Thought of the Nineteenth Century. \\ An Outline of the Penal Establishment in the History from Philosophy \\ A corrupção como delito no pensamento do século XIX. Um esboço de \\ sua conformação jurídico-penal na história desde a filosofia
}

\author{
MANUEl L. Ruiz-Morales ${ }^{\star}$
}

FECHA DE RECEPCIÓN: 10 DE ENERO DE 2019. FeCHA DE APROBACIÓN: 8 DE ABRIL DE 2019

Doi: http://dx.doi.org/10.12804/revistas.urosario.edu.co/sociojuridicos/a.7853

Para citar: Ruiz-Morales, M. (2019). La corrupción como delito del pensamiento en el siglo XIX. Un esbozo de su formación jurídico-penal en la historia desde la filosofía. Revista Socio-Jurídicos, 21(2), 331-356. Doi: http://dx.doi. org/10.12804/revistas.urosario.edu.co/sociojuridicos/a.7853

\section{RESUMEN}

El artículo estudia el proceso de conformación de la corrupción como conducta delictiva durante el siglo XIX por parte de los principales pensadores de dicho siglo. Se analizará, desde un enfoque histórico-filosófico, el significado penal que a partir de las revoluciones de finales del XVIII se le dio al fenómeno séptico. Igualmente, el trabajo atiende a los aspectos históricos, sociales, políticos y económicos del momento, ya que para comprender el sentido de las teorías filosóficas que vieron la luz en dicha centuria, se tienen que tener en cuenta estos aspectos circunstanciales anejos. Finalmente, se podrá observar las soluciones planteadas durante mencionado siglo desde un plano filosófico, que serán primordialmente de corte utilitarista, por tanto, probablemente aplicar las propuestas de lucha frente a la corrupción de los grandes pensadores de la Historia de la Humanidad podría ser una respuesta eficaz al fenómeno séptico, toda vez que las medidas utilizadas hogaño parecen caracterizarse por su escasa innovación, habiendo desarrollado los filósofos propuestas más ambiciosas en el campo de la contención y de la eliminación de la corrupción desde la Antigüedad.

Palabras clave: corrupción, delito, filosofía, siglo XIX, soluciones.

* Docente e investigador en formación de la Universidad de Cádiz (España), Dpto. de Derecho Internacional, Penal y Procesal. Adscrito al Instituto Andaluz Interuniversitario de Criminología. Profesor invitado en la Facultad de Derecho de la Universidad de Buenos Aires. Investigador invitado del Instituto de Investigaciones Jurídicas y Sociológicas Ambrosio L. Gioja (UBA). Correo electrónico: manuel.ruizmoral@uca.es. ORCID: https://orcid.org/0000-0003-2381-1503. 


\section{ABSTRACT}

This article analyses from a historical and philosophical approach corruption's establishment as an offensive or criminal behavior by the thinkers of the nineteenth century. Accordingly, it will study the illegal meaning given to the corrupt-operations during that century. Nevertheless, this writing will also attend to other historical and political aspects in order to contextualize and facilitate the understanding of the analysis because a moment's specific thought is indissoluble to its appended circumstances. Finally, it will observe the nineteenth century proposed solutions from a philosophical point of view of mainly utilitarian nature. Therefore, if the governments around the world implemented the anti-corruption proposals of the great thinkers of the history of humanity, it would respond effectively against corruption probably. Thus, the initiatives for combating the corruption nowadays haven't undergone significant innovations, while the philosophers -from ancient times- built mechanisms anti-corruption more ambitious.

Keywords: Corruption, crime, philosophy, nineteenth century, solutions.

\section{RESUMO}

O artigo estuda o processo de conformação da corrupção como conduta delitiva durante o século XIX por parte dos principais pensadores de dito século. Se analisará, desde um enfoque histórico-filosófico, o significado penal que a partir das revoluções de finais do XVIII se lhe deu ao fenômeno séptico. Igualmente, o trabalho atende aos aspectos históricos, sociais, políticos e econômicos do momento, pois para compreender o sentido das teorias filosóficas que surgiram em dito século, se têm que ter em conta estes aspetos circunstanciais alheios. Finalmente, se poderá observar as soluções apresentadas durante o mencionado século desde um plano filosófico, que serão primordialmente de corte utilitarista, portanto, provavelmente aplicar as propostas de luta frente à corrupção dos grandes pensadores da História da Humanidade poderia ser uma resposta eficaz ao fenômeno séptico, toda vez que as medidas utilizadas parecem caracterizar-se por sua escassa inovação, tendo desenvolvido os filósofos, propostas mais ambiciosas no campo da contenção e da eliminação da corrupção desde a Antiguidade.

Palavras-chave: corrupção, delito, filosofia, século XIX, soluções. 


\section{Introducción}

Aun cuando la corrupción parece ser un fenómeno que se desarrolla hogaño en las sociedades de nuestros días, ${ }^{1}$ la realidad es que las prácticas de carácter séptico son un problema inherente al ser humano y a la vida que este desarrolla en sociedad, por ello parece lógico que la corrupción haya estado ligada al hombre desde el surgimiento de las primeras sociedades. $^{2}$

Por tanto, no debe resultar extraño que, hace unos cinco mil años, el propio Código de Hammurabi ya tipificase conductas corruptas por parte de aquellos ciudadanos que ostentaran el cargo de juez (Franco, 1962, p. 335). Estas figuras delictivas hoy día se encuadrarían en tipos penales cercanos a la prevaricación, el cohecho o el tráfico de influencias.

Posteriormente, durante el Antiguo Egipto también se produjeron prácticas consideradas como corruptas, de ahí que hayan aparecido vestigios y normas en los que se alude a la corrupción. ${ }^{3}$ Sin embargo, el periodo de la Antigüedad en el que más medidas de lucha contra la corrupción se tomaron fue en el de la Grecia clásica, ante la aparición constante de algunos escándalos por dicho fenómeno. Además, esta preocupación vino de la mano de las tesis defendidas por Platón y por su discípulo Aristóteles, los cuales le dieron una importancia vital a la educación de los individuos desde su infancia, al carácter virtuoso de los gobernantes $-\mathrm{y}$ la necesidad de una educación específica para ellos-, y a la fijación de instituciones de control de la administración gubernativa

1 En este sentido, basta con hojear las páginas de cualquier diario o periódico, ya sea en formato papel o digital. De este modo, deteniéndonos en las noticias que aparecieron el 20 de diciembre de 2018, se pueden observar una decena de informaciones acerca de la corrupción. Entre ellas, se puede mencionar, v. gr. (20 de diciembre de 2018). Un informe de la Guardia Civil reactiva la investigación sobre la caja b del PP de Aguirre, El País Recuperado de https:// elpais.com/politica/2018/12/20/actualidad/1545329077_709322.html; (20 de diciembre de 2018). El fiscal general de Perú intensifica la presión contra el equipo que investiga el "caso Lava Jato". El País. Recuperado de https://elpais.com/internacional/2018/12/19/america/1545260191_236403.html; (20 de diciembre de 2018). La Fiscalía brasileña acusa a Temer de corrupción y de blanqueo. El País. Recuperado de https://elpais.com/internacional/2018/12/20/ america/1545261437_941660.html.

2 "En la antigüedad, engrasar las ruedas era una costumbre tan difundida como hoy y considerada en algún caso incluso lícita" (Brioschi, 2004, p. 193).

3 Se está haciendo alusión -entre otros- al Decreto de Horemheb, o las medidas impuestas por Ramsés III (Fernández Aguado, 2013, pp. 103-105; Zingarelli, 2016, pp. 53-57). 
y de las funciones desarrolladas por los ciudadanos que ostentaban el poder, reprochando la utilización de su imagen proyectada para lograr objetivos individuales particulares (Ruiz-Morales, 2018, pp. 309-320).

No obstante, a partir del dominio de Roma la corrupción se instauró en el sistema social como modo de vida, y aunque hubo algunos emperadores que se caracterizaron por la mesura y la aplicación práctica de la filosofía estoica (Zavala Treviño, 2013, pp. 32-34) -incluso mediante la promulgación de algunas leyes anticorrupción (Burkhardt Pérez, 2013, pp. 9-14)-, esa no fue la tónica dominante. Por ello no debe extrañar que un vasto imperio como el Romano cediera ante las invasiones de tribus menores, toda vez que la corrupción logró degenerar la totalidad de las instituciones romanas.

Posteriormente, en los primeros siglos del Medievo, la influencia de la moral cristiana, que se extendió por toda Europa a partir de la conversión al cristianismo del Emperador Constantino, se hizo notar en las prácticas corruptas, toda vez que estas se consideraban insertas en el mandato de Dios de "No robarás" (Zavala Treviño, 2013, p. 37; González, 2011, s. p.). No obstante, con el paso de las centurias el comportamiento social global tendió hacia el relajamiento, hacia la laxitud, incluso en el seno de la Iglesia, ante lo cual surgieron las órdenes mendicantes, que criticaban las actitudes del papado y la evolución tomada en el interior del cristianismo (Carpintero Benítez, 2011, p. 10; González, 1995, pp. 13-14).

Finalmente, el renacimiento inició la senda hacia un florecimiento cultural y científico que culminaría en el siglo XVIII (Sciacca, 1960, pp. 7-9) con las tesis ilustradas que serían el germen intelectual de las revoluciones de finales de dicha centuria y principios de la siguiente. No obstante, durante la Edad Moderna la corrupción se mantuvo como consecuencia del sostenimiento de los últimos visos del feudalismo y de la relevancia alcanzada por las monarquías absolutas europeas. Además, el descubrimiento del "Nuevo Mundo" creó rutas comerciales desde y hacia la metrópoli, lo que favoreció la consolidación de prácticas coadyuvantes de la corrupción, tal y como ocurre con el blanqueo de capitales al estilo que se conoce hoy en día. En el plano filosófico, fueron destacable las innovaciones en la lucha anticorrupción de Maquiavelo, proponiendo una especie de tribunal del jurado para el juzgamiento de las causas por corrupción (Maquiavelo, 2004, pp. 79, 120, 141-160)-, la fortaleza y el carácter inexpugnable del control 
funcionarial por parte del monarca -según las tesis hobessianas (Hobbes, 2004, pp. 245-252) - o de la judicatura -de acuerdo con el pensamiento de Locke (Locke, 2003, pp. 100-105) -, y la labor pedagógica-educacional de Rousseau (Rubio Carracedo, 2009, pp. 222-224).

\section{La era de las revoluciones fruto de las ideas iluministas}

Durante el siglo XVIII la obra y el pensamiento de los filósofos ilustrados, ${ }^{4}$ especialmente franceses, como Montesquieu, Voltaire o Rousseau ${ }^{5}$ se difundieron rápidamente fuera de las fronteras galas, lo que dio lugar a un gran fenómeno consistente en el asentamiento y desarrollo político de los postulados ideológicos de la Ilustración ${ }^{6}$ por todos aquellos lugares a los que se iban expandiendo, apareciendo políticos, teóricos, filósofos y pensadores que defendían corrientes de pensamiento afrancesadas y/o ilustradas en las distintas naciones.

La divulgación de estos ideales en la masa popular posibilitó la agitación y la insurrección de las clases más hostigadas por las últimas resonancias del régimen feudal, encarnado en el absolutismo político monárquico, lo que provocó levantamientos masivos de ciudadanos, nativos o indígenas a un lado u otro del Atlántico, según las circunstancias. Estas sublevaciones serán las revoluciones civiles y burguesas de finales del XVIII y de inicios

4 El prusiano Immanuel Kant aludió desde la perspectiva de la moral a la corrupción de los políticos. Desde sus obras - aun cuando no fueran estrictamente de filosofía política- se puede diferenciar entre el político moral, es decir, el que usa la moral para sus actuaciones públicas y personales y, por tanto, actúa con transparencia y publicidad en base a la justicia, y el moralista político, que usa la moral como un instrumento de persuasión, para después someterse a la actuación secreta y a la corrupción, en base al pragmatismo. Ello evidentemente es la consecuencia de aplicar o no aplicar en la vida, el imperativo categórico (Flores Vega, et al., 2008, pp. 46-60; Kant, 1999, pp. 113-128).

5 Por mencionar algunos, sin afán de exhaustividad.

6 La Ilustración cultivó también otros campos además del filosófico, como el matemático, el físico, el médico-sanitario, etc., siguiendo la senda evolutiva del siglo XVII como Era de la Razón. De este modo, autores como Descartes, Spinoza, Pascal, Leibniz, Newton o algo antes Galileo, son precursores de la Ilustración y exponentes de la revolución científica que se venía gestando esos años. Contemporáneo a Newton era Locke, el cual influyó en los franceses Voltaire y Rousseau. Entre otros reseñables "ilustrados" se hallan Montesquieu, Diderot, D'Alambert, Hutcheson, Hume, Helvecio, Wolff, Kant, Beccaria, Galiani, Filangieri, Franklin, Jefferson, Paine, Feijoo, Mayans, Jovellanos, Cadalso, Campomanes, Capmany, Mutis, Bernoulli, Euler, Lagrange, Laplace o Lavoisier, entre otros. 
del XIX, que en todo caso abroquelarán las consideraciones doctrinales del Siglo de las Luces.

\section{Revolución de las Trece Colonias e Independencia Estadounidense}

En torno a 1763 comenzaron los actos de oposición de las colonias del Imperio Británico a su propia metrópoli, puesto que existía un injusto sistema político, en virtud del cual sólo los funcionarios enviados desde las islas podían desarrollar la carrera política o militar, sin ninguna posibilidad de que los pobladores de la colonia pudieran beneficiarse del régimen funcionarial de ascensos.

Junto a este asunto, se produjo la promulgación de ciertas normas legales que imponían considerables gravámenes a los colonos, como la Ley del Azúcar o del Timbre, cuya verdadera finalidad era la de sufragar los costes de mantenimiento de la administración en los dominios y las necesidades de financiación de la Corona Británica (Téllez Alarcia, 2001, pp. 22-24).

Ello propició el inicio turbulento de sendos levantamientos a lo largo de los años, hasta la consecución de la definitiva emancipación de los Estados Unidos.

Los basamentos utilizados por los colonos se hallaban en las tesis ilustradas, ya que los insurrectos consideraban estas tasas ilegítimas, al no poder hacer valer sus derechos como ciudadanos ingleses, puesto que tampoco contaban con representación en las cámaras parlamentarias, por esa razón, el lema usado durante aquellos momentos fue "No Taxation without representation", 7 al considerarse la situación como un abuso unilateral por parte del gobierno de Reino Unido, toda vez que ese Parlamento no podía personificar los intereses nacionales de los colonos estadounidenses al carecer estos de portavoces en él.

Ese es el motivo por el cual en el modelo norteamericano existió desde el origen una ligera imposición del poder judicial sobre el legislativo. Esta prevalencia del poder judicial fue consecuencia del temor existente alrededor de la figura del legislador, por lo que dicha preeminencia jugó como una especie de prevención para que no volviera a producirse ese

\footnotetext{
7 Ningún impuesto sin representación, ramificación de "quod omnes tangit ab ómnibus approbari debet".
} 
predomino impuesto por parte del poder legislativo, como había ocurrido durante el sometimiento anglosajón.

Ahora bien, lo expuesto en el párrafo anterior, no significó que el sistema no impusiera e imponga aún mecanismos de control, sino todo lo contrario. Respecto al poder ejecutivo se estableció la fórmula del impeachment para remover y procesar a los cargos públicos que cometieran algún delito, especialmente, los relativos a su función. En relación al poder judicial, éste -todavía hoy- se encuentra encorsetado a la rigurosa aplicación de la ley (De Almeida Mendoça, 2013, p. 40).

\section{La Revolución Francesa y el Imperio Napoleónico}

La experiencia francesa consistió, por su parte, en la ruptura total con el Antiguo Régimen, a través de la abolición de los aspectos feudales que seguían normalizando la vida gala, en la que el pueblo o Tercer Estado con su esfuerzo, trabajo y represión fiscal debía sostener a las clases nobiliarias, al alto clero y a la propia realeza, que era la primigenia e inveterada fuente de opresión, en virtud de los privilegios de los que gozaban.

Ante las premisas ideológicas divulgadas por parte de los philosophes, la ciudadanía comenzó a ser consciente de los atropellos que venían dándose por parte del rey y los gobernantes. Para las clases más bajas, ellos eran los responsables de su situación deficitaria en casi todos los aspectos de la vida, porque los estamentos privilegiados vivían de una manera acomodada, plácidamente, sin deber de atender siquiera a las obligaciones impositivas, a costa de un pueblo llano que, en tal situación, en ningún caso podía prosperar debido a la subyugación a la que se veía sometido irremediablemente.

Así las cosas, Liberté, egalité, fraternité fue el lema de la Revolución; eran estos los principios por los que luchaban aquellos hombres que, fundamentalmente, recelaban de todo el aparato gubernamental. Desconfiaban de una monarquía flemática ante el sufrimiento de la población y de unos órganos jurisdiccionales compuestos por jueces corruptos que velaban por los intereses de sus iguales.

Por ello, en el particular francés se optó por la imposición de un legislador virtuoso sobre los demás poderes constituidos, que, además, se opusiera a las prerrogativas absolutistas, representando la verdadera 
voluntad general. ${ }^{8}$ Ese es el motivo por el que la facción jacobina de los revolucionarios se decantó por la representación directa en la que el pueblo acudía habitualmente al Parlamento, así como por la creación de una serie de garantías sociales ${ }^{9}$ para los individuos desdichados (De Almeida Mendoça, 2013, pp. 40-41).

Sin embargo, aunque el espíritu revolucionario pretendía enarbolar una serie de derechos fundamentales básicos para todos los seres humanos -al igual que la puesta en marcha de la tesis de la separación de poderes y la limitación del poder de la corona- ${ }^{10}$ tras la caída de la monarquía se continuaron produciendo abusos flagrantes, como los acaecidos durante el Reinado del Terror en el que Maximilien Robespierre "el Incorruptible" no tuvo reparos en guillotinar a aquellos que discrepaban mínimamente de su opción política (Péronnet, 1984, pp. 253-259), a través de su posición en el Comité de Salvación Pública. ${ }^{11}$

Durante esos años ya venía apareciendo por el París revolucionario un general de brigada conocido como Napoleón Bonaparte. Este, al mando de los Ejércitos Franceses, obtuvo grandes victorias en sus campañas de Italia, ${ }^{12}$ Egipto e, incluso anteriormente, había logrado contener a las fuerzas insurgentes realistas y contrarrevolucionarias, que ponían

$8 \quad \mathrm{Al}$ estilo explicado por Rousseau. En este sentido, decía el ginebrino "hemos de distinguir en la persona del magistrado tres voluntades esencialmente diferentes. Primera, la voluntad propia del individuo, que tiende a su ventaja particular; segunda, la voluntad común de los magistrados, que se orienta únicamente a la ventaja del gobierno, y que puede denominarse voluntad de cuerpo, la cual es general con relación al gobierno, y particular con relación al Estado, del que el gobierno forma parte; tercera, la voluntad del pueblo o voluntad soberana, que es general tanto con relación al Estado considerado como un todo, como con relación al gobierno considerado como parte del Estado. En una legislación perfecta, la voluntad particular o individual debe ser nula, la voluntad de cuerpo propia del gobierno debe estar muy subordinada y, por consiguiente, la voluntad general o soberana debe ser siempre dominante y la regla única de las otras dos" (Rousseau, 2005, pp. 65-66).

9 No obstante, como se verá más adelante, el Estado Liberal que nace con estas revoluciones, no logra conformar por sí solo un Estado Social, de ahí que durante el siglo XIX continúen las revueltas a lo largo y ancho del mundo, incluso en Francia, ya que se producirán años más tarde las denominadas Revoluciones Liberales Burguesas.

10 Se está aludiendo a la Declaración de los Derechos del Hombre y del Ciudadano de 1789 y a la Constitución de 1791.

11 Institución que curiosamente en su intento por lograr un prototipo de Francia abogaba por la eliminación de la corrupción, el acaparamiento y basar la política en principios como el humanitarismo, el idealismo social, la laicidad y el amor patrio.

12 A la muerte de Robespierre, Napoleón fue acusado de traición y dilapidación de fondos públicos. 
en peligro el devenir del progreso insurrecto. Todo ello fue invistiéndole de popularidad y se granjeó el agrado del Directorio, ${ }^{13}$ adquiriendo al poco tiempo el papel de personaje influyente de la política francesa en esa nebulosa social (Manfred, 1988, pp. 77-90).

Mientras Napoleón se hallaba en sus campañas egipcias, la situación político-militar de Francia se veía coartada, al haber sufrido dicha nación varias derrotas en sus enfrentamientos contra Austria, Reino Unido o Rusia. Ante esos acontecimientos nada esperanzadores, el Directorio, debilitado por la quiebra financiera de las arcas públicas, sospechaba de una inminente invasión de las potencias extranjeras, lo que provocó la entrada en París del de Ajaccio, tomando el poder junto a sus tropas y proclamando el Consulado (Manfred, 1988, pp. 213-227).

Posteriormente, durante los años de mandato napoleónico -tanto en forma de Cónsul Vitalicio como bajo el título de Emperador- se realizaron numerosas reformas normativas en todas las ramas del ordenamiento jurídico. ${ }^{14}$ Napoleón modificó diametralmente la administración francesa, e incluso promulgó un Código Penal; no obstante, a pesar de sus esfuerzos en materia legislativa, el Pequeño $\mathrm{Cabo}^{15}$ no pudo o no quiso eliminar la corrupción de los funcionarios en el ejercicio de sus funciones, toda vez que la promovía al preconizar que a los ministros les estaba permitido apropiarse de caudales públicos, en tanto no fuesen grandes cantidades y la gestión en sus labores fuese eficiente (Grande Chica, 2014, p. 64; Brioschi, 2004, p. 112; Almeida Mendoça, 2013, p. 41).

Tanto es así, que el propio Emperador de los franceses se sirvió de prácticas de dudosa legitimidad, lejanamente basadas en el mérito y la capacidad, e inherentes a una burocracia administrativa plenamente republicana a la hora de dirigir sus territorios conquistados. Y es que el de Córcega utilizó audazmente las prácticas familistas sin reparo alguno, toda

13 Bonaparte manejaba los medios de comunicación, ya que durante esos años creó varios periódicos y reprimió con fuerza los intentos de llegada al poder de los partidarios de la monarquía o de los grupos más moderados como los girondinos, a través de algunos golpes de Estado.

14 Napoleón emprendió el movimiento codificador, uniendo en un cuerpo único las leyes civiles francesas, en el Código Napoleónico. Sin embargo, sus esfuerzos de codificación y de ordenación de la normativa francesa ocupó a todas las ramas del Derecho, desde el tributario, el procesal, el penal o el mercantil.

15 Este es uno de los apodos de Napoleón entre la tropa, debido a su escasa altura. 
vez que no existen otros modos de comprender cómo sus más allegados ostentaron la figura de máxima autoridad en los territorios ocupados. ${ }^{16}$

Ante dicha experiencia no es de extrañar que unos años más tarde, Alexis de Clérel, vizconde de Tocqueville, explicara que existía "algo de grosero, vulgar y depravado en la práctica corrupta de aquellos que llegan por casualidad al poder" (Tocqueville, 1957, p. 233), puesto que entran en juego conductas como compras de favores, votos, sobornos, etc.

Hasta tal punto se extendía la corrupción en esos años, que incluso la definitiva caída de Bonaparte tras su derrota en la batalla de Waterloo vino de la mano de ciertas conductas de dudosa licitud -al menos si se observa con los cánones actuales-. De este modo, durante las guerras napoleónicas la corona británica le encomendó a una familia banquera de origen judeo-alemana, los Rothschild, que fuese la suministradora de los recursos financieros para las campañas militares. Por esa función se le otorgaba en torno al cinco por ciento del total en concepto de comisión. Así, tras la reaparición del Emperador francés en 1815, Nathan Rothschild consiguió para el duque de Wellington y su ejército cerca de diez millones de libras en oro, aunque en principio sólo eran necesarios dos millones. No obstante, pensaba mantener el negocio durante un largo periodo, de ahí su prevención y su acumulación. Sin embargo, las tropas francesas fueron superadas demasiado pronto, sus cálculos fallaron, y en aquel momento contaba con ocho millones líquidos destinados a guerras que ya habían acabado, por lo que la corona no iba a sufragar esa pérdida. Además, inminentemente se produciría una depreciación del precio del oro, al descender brutalmente la demanda del mismo. Por ese motivo, el mediano de la familia banquera tenía que buscar una solución si no quería sufrir en sus arcas unas pérdidas millonarias. Para ello tuvo que utilizar sus influencias, aprovechando el conocimiento de la victoria aliada en la Colina del León dos días antes de que las autoridades oficiales conociesen el suceso y el mismo se hiciera público; esto fue lo que lo llevó a realizar una compra masiva de bonos estatales con los excedentes de oro que se desplomarían días más tarde, buscando un valor seguro para sus fondos. De este modo, al acabar las maniobras militares, en los

16 A título de ejemplo, cabe mencionar a José I Bonaparte como Rey de España, Luis Napoleón Bonaparte como Rey de Holanda, Jerónimo I Bonaparte como Rey de Westfalia o Joachim Napoleón Murat como Rey de Napolés. 
años siguientes las arcas británicas no necesitaron de tantas cantidades monetarias, lo que produjo una mayor reserva en el Tesoro Público británico, como consecuencia de la venta de instrumentos financieros de deuda. Ello elevó el dinero en circulación, la normalizó e incrementó las compras, provocando una inflación y un crecimiento económico que le hizo multiplicar ingentemente las sumas invertidas (Ferguson, 2009, s.p.) al dirigente de la rama británica de la banca de la familia Rothschild. ${ }^{17}$

\section{Las medidas de la Constitución de 1812}

Otro ejemplo más de la preocupación existente sobre la apropiación de caudales públicos por gobernantes y funcionarios se encuentra en la Constitución de Cádiz.

Este texto constitucional nacido de las Cortes Constituyentes reunidas en la Isla de León, y posteriormente en la capital gaditana durante la Guerra de Independencia Española, contaba con un Título, "De las contribuciones" en el que se regulaba los aspectos relativos a la Hacienda Pública.

Lo relevante en este particular es que en su art. 350, se refería a la Contaduría Mayor de Cuentas, que llevaría a cabo la supervisión de todo lo referente a las arcas estatales, promoviéndose de este modo la incorporación en el rango constitucional del control del gasto público, para lograr un adecuado funcionamiento de la sociedad democrática. Además, este órgano y su funcionamiento, en virtud del mencionado artículo, debía de regularse en una ley especial.

Así, esta previsión constitucional posibilitó la posterior elaboración de multitud de normas jurídicas de distinto rango, que vinieron a ordenar y sistematizar los procedimientos público-contables, fijaron el concepto de fondo público y allanaron el camino para el establecimiento del actual Tribunal de Cuentas español (Vacas García-Alós, 2012, pp. 385-388). ${ }^{18}$

17 Igualmente, los Rothschild tenían el negocio asegurado, puesto que eran los prestamistas de los distintos gobiernos del mundo, atendiendo a las diversas ramas instituidas en cada centro comercial europeo, por cada uno de los cinco hijos de Mayer Amschel Rothschild.

18 Curiosamente, hace escasamente unos días, ese Tribunal de Cuentas condenó a Ana Botella, esposa del expresidente del gobierno español José María Aznar y exalcaldesa del Ayuntamiento de Madrid, y a otros dirigentes al pago de 26 millones de euros. En este sentido, véase (28 de diciembre de 2018. Botella y 7 excargos de Madrid, condenados a pagar 26 millones por malvender pisos públicos a fondos buitres. El País. Recuperado de https://elpais.com/politica/2018/12/28/actualidad/1545982331_650044.html 
Ahora bien, una Instrucción de 1820 desarrolló el mandato constitucional, estableciendo que los Ministerios, las autoridades y los funcionarios que administrasen los caudales del Estado debían rendir cuentas de su actividad. Igualmente, dicha instrucción fijó el deber de informar de los desfalcos, apropiaciones o malversaciones, para las cuales se aplicarían sanciones ante la sola aparición de falsedades o defectos en el manejo del Tesoro Público.

A mayor abundamiento, es destacable la creación de órganos especiales en la materia, como es el caso del Fiscal Togado. Esta nueva institución ejercía sus funciones jurisdiccionales ante la Contaduría.

Por otra parte, otras normas posteriores cuyas raíces se hallaban en "La Pepa", ${ }^{19}$ fijaron los delitos en los que incurrían los funcionarios que presentaban las cuentas o documentos contables con errores o en plazo vencido (Vacas García-Alós, 2012, 389-390).

De igual modo, la constitución gaditana respecto a la organización en la celebración de las Cortes, reglamentaba en los arts. 129 y 130 la imposibilidad de usar su influencia como diputado para obtener favores en su persona o en la de otro, como intento de eliminar el amiguismo, el enchufismo y prácticas cercanas al actual cohecho. ${ }^{20}$

\section{La situación en Hispanoamérica}

Los primeros años del siglo XIX fueron también relevantes para los territorios dominados por España en América, ya que surgieron procesos independentistas ${ }^{21}$ a lo largo y ancho del continente que, antes de acabar

19 Nombre de la Constitución de Cádiz de 1812 en el ámbito de la ciudadanía local, por ser promulgada en la onomástica de San José, cuyo hipocorístico es Pepe. La ciudadanía gaditana vitoreaba por sus calles "iViva la Pepa!" entre gritos de júbilo.

20 Art. 129 de la Constitución de 1812: “Durante el tiempo de su Diputación, contado para este efecto desde que el nombramiento conste en la permanente de Cortes, no podrán los Diputados admitir para sí, ni solicitar para otro empleo alguno de provisión del Rey, ni aún ascenso, como no sea de escala en su respectiva carrera". El Art. 130 del mismo texto constitucional dice: "Del mismo modo no podrán durante el tiempo de su Diputación, y un año después del último acto de sus funciones, obtener para sí, ni solicitar para otro pensión, ni condecoración alguna, que sea también de provisión del Rey".

21 El bando revolucionario se amparaba en las ideas de la llustración, siguiendo el modelo de la Independencia de Estados Unidos, la Revolución del pueblo francés, o la propia guerra de Independencia del Pueblo español contra las tropas napoleónicas. Igualmente, se fue creando cierta conciencia nacional al instaurarse en el continente americano distintas Juntas de Gobierno, 
el primer cuarto de ese nuevo siglo, habían dado lugar a una serie de nuevos Estados soberanos.

Ante el conocimiento de la instauración del fenómeno de corrupción como un mal endémico, siendo parte misma del sistema burocrático y del funcionamiento administrativo de los virreinatos, es dable destacar cómo Simón Bolívar en 1813 fijó la pena de muerte -serían pasados por las armas, decía- para aquellos que realizaran alguna actividad defraudadora relativa a la renta surgida del tabaco, ${ }^{22}$ toda vez que el cultivo y el comercio de mencionada planta era fundamental para las arcas estatales (Bolívar, 2009, pp. 30-31). Posteriormente, en 1826 declaró la pena de muerte para todo aquel funcionario que se apropiase al menos de diez pesos, ya que para el Libertador ${ }^{23}$ la corrupción era considerada una violación del interés público (Coronel, 2006, p. 2). De todas maneras, la corrupción continuó en Venezuela, con actividades sépticas de toda índole. ${ }^{24}$

Lo mismo vino ocurriendo en la totalidad de los nuevos países latinoamericanos tras la emancipación de la metrópoli, puesto que la corrupción siguió invadiendo el tejido político y social, auspiciando las desigualdades sociales en cada uno de estos Estados, debido principalmente a las costumbres y usos que hacían que el autor de tales conductas quedase sin castigo. En algunos casos, se intentó reformar el sistema de acceso del funcionariado, retribuir la función pública de una mejor manera, establecer cargos vitalicios y la carrera interna; en otros lugares, se achacó el problema a la época colonial y a las decisiones gubernamentales de regímenes autoritarios que disponían de las arcas estatales con absoluta impunidad (Zavala Treviño, 2013, p. 53; Meza Ingar, 2002, pp. 85-87).

autónomas a la Junta Suprema Central, así como mediante la defensa de los territorios por las propias fuerzas virreinales ante invasiones de potencias extranjeras, sin mediar ni intervenir siquiera las flotas españolas que fueron mayoritariamente destruidas en Trafalgar. Además, la Constitución gaditana de 1812 y sus ideales liberales, sirvió de base al constitucionalismo americano, pero alentó los temores criollos de equiparación en derechos con los indios. Éstas son las principales circunstancias que dieron lugar a la Independencia de las colonias españolas, entre otras muchas.

22 Se entendía cometida dicha actividad fraudulenta por la simple venta clandestina fuera de los Estancos, así como por el robo o la malversación de estas rentas esenciales para el funcionamiento estatal, hasta el punto de que se establecía para estos casos un procedimiento sumario y recias represalias hacia los juzgadores que mitigaran las consecuencias de los acusados por tales conductas. Vid. Ley firmada el 11 de septiembre de 1813 en su cuartel General frente a Puerto cabello.

23 Para autores como Marx, el propio Bolívar era un dictador corrupto, que saqueaba a su pueblo, mientras hacía prevalecer a la nobleza criolla a la que pertenecía.

24 V.gr. El nepotismo en época de los hermanos Monagas (Salcedo Bastardo, 1977, p. 425). 


\section{La Revolución Industrial ${ }^{25}$}

Desde la segunda mitad del siglo XVIII hasta la mitad de la centuria siguiente, ${ }^{26}$ se produjo una evolución económica, social, demográfica y tecnológica sin precedentes en la historia de la humanidad, que provocó una alteración en los modos de vida tradicionales, puesto que se origina un masivo traslado de habitantes desde el campo hacia las ciudades, denominada éxodo rural, en busca del trabajo sito en los núcleos urbanos donde se localizaban las fábricas. ${ }^{27}$

Esta nueva forma de vivir, tras la aparición de las factorías, se caracterizó por el uso de nuevas técnicas ${ }^{28}$ de producción y por la aplicación de la máquina de vapor modernizada por James Watt, tanto a la actividad productiva propiamente dicha como a los medios de transporte ${ }^{29}$ que posibilitaron el desarrollo comercial.

Todo ello tendrá consecuencias importantes; ${ }^{30}$ en primer lugar, surgió una nueva clase social, la clase obrera, cuya situación llegó a ser bastante precaria, dando lugar a movimientos ideológicos y políticos. En segundo lugar, la nueva industria requería de una fuente de energía con alto poder calorífico, el carbón, lo que provocaría la extracción y explotación de este mineral. En tercer término, las mejoras en los productos, en el acceso a mayor cantidad de alimentos y de productos higiénicos, así como la mejora en la salubridad de las ciudades, redundó en un crecimiento sin precedentes de la población, lo que la retroalimentaría circularmente en el desarrollo económico, al existir un mercado potencial mayor para los bienes y servicios producidos por la mencionada joven industria.

25 Algunos autores explican que el término revolución es desmesurado, ya que no se trató de un cambio radical, sino que el proceso fue gradual.

26 Los historiadores y economistas, no se ponen de acuerdo en las fechas de inicio y final de este periodo.

27 Por tanto, se trasladó la primacía desde el sector primario al sector secundario de la economía, desde la economía tradicional basada en la agricultura y la ganadería a la economía industrial.

28 Se abandonó la conciencia que unía al hombre con la herramienta, pasándose a unirse a la máquina.

29 Con la invención del ferrocarril y del barco a vapor.

30 Piénsese que simultáneamente se estaban produciendo los movimientos independentistas coloniales, la revolución francesa, las guerras napoleónicas, las revoluciones liberales burguesas, etc. 
El padre de la economía moderna escribió en 1776 su más influyente obra, La riqueza de las naciones, en la cual criticaba los principios económicos reinantes en el Absolutismo, así como las tesis mercantilistas que surgieron desde el siglo $\mathrm{XV}$, para defender que el bienestar social venía de la mano del crecimiento económico, y este se conseguía mediante la división del trabajo y la libre competencia (Smith, 1794, pp. 7-27), estableciendo las bases del capitalismo industrial $\mathrm{y}$, en parte, del liberalismo económico, ${ }^{32}$ pilares ambos en los que se asentaría la Revolución Industrial (Enríquez Pérez, 2008, pp. 18-23).

Smith no negaba la intervención del Estado, que debía actuar en la economía sufragando a través del presupuesto público los gastos de defensa, justicia y respeto a las libertades, creación de infraestructuras o los de educación; sin embargo, vituperó las subvenciones, los aranceles aduaneros y las leyes que fijaban monopolios legales, entre otras. Ello es así porque para este escocés eran estas formas de intervención estatal las que promovían la corrupción y la conservación de la riqueza en manos de los poderosos y terratenientes, a través de la limitación competencial. De ahí que existiese una "mano invisible" 33 que garantizaba la consecución del bien para todos, ya que la persecución de cada cual de su propio interés individual actuaba como un sistema equilibrador de fuerzas en virtud de las inclinaciones de los demás sujetos (Grande Chica, 2014, p. 64).

31 A pesar de que cronológicamente debería ser considerado como un Ilustrado, en este trabajo se estudia tras la Revolución Industrial -o mejor dicho, en ella- porque sus teorías de economía política se desarrollaron durante ese procedimiento de cambio. A mayor abundamiento, debe tenerse en cuenta que en la historia universal, la Ilustración, las revoluciones liberales y las transformaciones propias de la Industrialización fueron coetáneas en el tiempo y, por tanto, no se sucedieron tan estructuradamente como la sistematicidad literaria requeriría.

32 En cierto modo, fijó las bases del institucionalismo económico, porque reconocía un cierto papel a desarrollar por el Estado, por lo que no era puramente liberal.

33 Esta mano invisible y los mismos argumentos de Smith para apoyar su tesis, serán utilizados por otros muchos autores para desmedrar esta teoría, ya que la no intervención estatal hace que los poderosos sean los que tengan acceso a más productos, estando dispuestos a comprar a mayor precio, por lo que en el mercado imperfecto y real, la libertad de elegir la ofrece el dinero, facilitando la vuelta al favoritismo, la preferencia y la corrupción en definitiva (Sampedro, 2002, pp. 6-8). 
Ahora bien, el papel estatal también sería vital, toda vez que, como el hombre es avaro y egoísta naturalmente, su actividad debía estar mediatizada por una serie de reglas y valores institucionalizados por el Estado, de manera que esta estructura creada por el aparato gubernamental fomentara el interés público y limitara la libertad individual, moderando la naturaleza pasional del ser humano y el desorden (Enríquez Pérez, 2008, p. 25-26).

\section{Georg Hegel (1770 - 1831)}

Hegel, como creador del sistema dialéctico, que explicaba la historia de la filosofía, introdujo la dialéctica de ciertas instituciones, lo que puede ser aplicado a la corrupción. ${ }^{34}$ Por tanto, como ocurre con muchos tipos penales ligados al fenómeno séptico, por ejemplo, el cohecho, de acuerdo a la dialéctica de la corrupción se puede entender igualmente necesarios el corrompible que el corruptor, esto es, el agente activo y pasivo, ${ }^{35}$ y no pueden existir el uno sin el otro, ya que ambos son $\operatorname{corruptos}^{36} \mathrm{y}$ sus conductas son -análogamente- reprochables jurídico-penalmente hablando (Rodríguez Kauth, 1987, p. 18).

\section{Jeremy Bentham ${ }^{37}$ (1748-1832)}

El padre del utilitarismo emprendía su discurso en la teoría de la motivación humana, en virtud de la cual cada individuo actúa buscando su particular interés, su propio placer, mas de la misma manera, de acuerdo con las teorías utilitaristas formuladas por él, el objetivo último que se debía pretender era la mayor satisfacción o felicidadpara el mayor número de personas, contando todos por igual (Fernández Díaz, 2004, pp. 277-285).

No obstante, al existir en la sociedad dirigentes y dirigidos, ${ }^{38}$ el problema se hallaba en que los gobernantes se encontraban en un papel preponderante, ya que, además de velar y perseguir sus propias pasiones,

34 Hegel consideraba unida la decadencia a la corrupción (Hegel, 1821, pp. 422-423).

35 Estos roles son intercambiables según la situación.

36 Hegel explicó esta tesis respecto del esclavo (Hegel, 1966, pp. 113-120).

37 Téngase en cuenta la indicación advertida respecto a la explicación de Adam Smith y la Industrialización, ya que ocurre análogamente con las tesis utilitaristas benthamianas.

38 Los intereses de ambos grupos chocan diametralmente. 
contaban con los medios para hacer efectivo su consecución, lo que menoscaba los intereses de una amplia mayoría de la población.

Por este motivo es comprensible que Bentham explicase que la corrupción política no era una perversión del funcionamiento normal en la democracia representativa, sino que la entendía como un carácter sustancial e intrínseco a dicho sistema (Bentham, 1989, pp. 25-26), denominando corrupta ${ }^{39}$ a la actividad que favorecía la felicidad de unos pocos, desmedrando la beatitud del resto, esto es, siempre que no se promoviera el interés general existirían corruptelas. De este modo, parece lógico que fuera necesaria la elaboración de acuerdos constitucionales que impidieran las prácticas sépticas, garantizando que los regidores del Estado persiguieran sus inclinaciones, debiéndose perseguir y fomentar simultáneamente los de la generalidad, ya que, en otro caso, traicionarían la confianza depositada en ellos (Schofield, 2002, pp. 68-69).

Por otra parte, Bentham dividía en tres las formas de gobierno, a saber: los gobiernos puros o monarquías absolutas, las democracias representativas y los regímenes mixtos. Pues bien, en los primeros no podía existir corrupción, puesto que no habría ruptura de confianza en perjuicio del interés general, puesto que la ciudadanía no tiene representantes. Además, según su opinión, tampoco el soberano corrompía a sus funcionarios con promesas futuras, toda vez que le era más fácil usar la fuerza coercitiva para obtener sus placeres, al detentar todo el poder. En cambio, en los demás sistemas políticos si cabría tal posibilidad ${ }^{40}$ al entrar en juego estos representantes parlamentarios del legislativo, que velarían por sus intereses particulares haciendo uso de su poder y las relaciones instauradas en el régimen mencionado (Bentham, 1989, pp. 42-44). Ahora bien, como consecuencia de ello, se produciría un quebranto para la población en general, al tener esta que sufragar con sus impuestos a este núcleo subversivo (Schofield, 2002, pp. 72-73).

39 Explicó tan detalladamente la corrupción, que decía que todo acto séptico requería de dos agentes, el que ejercía la influencia corruptora y el que practicaba el servilismo corrupto. También analizó como debía ser la promesa de recompensa que en base a la confiabilidad entre los agentes producía la separación del gobernante o funcionario a las funciones de su cargo y a lo esperado por su parte como administradores públicos y garantes del patrimonio de todos.

40 Para Bentham el jefe del Ejecutivo era el "Corruptor General", al poder investir a multitud de cargos bajo su lecho, que era el objeto de deseo por toda la comunidad. 
Por último, el creador del Panóptico ${ }^{41}$ pensaba que la prevención de la corrupción a través de la prohibición legal de tales conductas y/o mediante el establecimiento de tipos penales no tenía sentido alguno, toda vez que siempre habría personas que ostentaran la potestad de nombrar cargos subordinados remunerados y, por ende, ello sería suficiente para quebrantar todas las aspiraciones (Schofield, 2002, pp. 73-74). Ahora bien, Bentham desarrolló el remedio jurídico capaz de paliar tal situación. Así las cosas, se decantó por la comprobación y verificación en la observancia de los intereses de un mayor número de personas por medio de la celebración de elecciones realizadas anualmente y con voto secreto, lo que debía permitir a los ciudadanos ensalzar a aquel representante que surtía en su persona de una mejor manera su propio interés. Además, al componerse el Parlamento con tal habitualidad, los miembros del legislativo intentarían favorecer los deseos del mayor número de personas, incluso pretenderían velar por el interés universal, ya que si los electores percibían un alejamiento en relación a la utilidad proporcionada, optarían por no reelegirlo.

Paralelamente, este filósofo inglés fijaba otra serie de medidas alternativas como la sumisión de los poderes ejecutivo y judicial al legislativo, ostentando el liderazgo de los mismos sujetos o miembros adscritos al parlamento. ${ }^{42}$ De este modo, la ciudadanía podría valorar su función en los comicios, por lo que la actuación normalizada en el puesto de gobernante o funcionario vendría de la mano del poder puesto en el pueblo de remoción de estos cargos, ${ }^{43}$ incluso si lo solicitase la mayoría, con anterioridad a la celebración de las elecciones anuales (Schofield, 2002, pp. 75-77).

${ }^{41}$ Bentham también ideó esta estructura en la cual el centro servía para vigilar todo desde ese punto, sin ser visto, y que fue utilizado en penitenciarias y escuelas, y posteriormente en fábricas.

42 Por medio de un primer ministro y del ministro de justicia, por ejemplo.

43 Indicó Bentham unas medidas complementarias, como la supresión de potestades en el nombramiento de funcionarios o, al menos, minimizar esa posibilidad. También, el fijar un considerable valor de las retribuciones, haciendo menos atractivo el llevar a cabo esas conductas. De todas maneras exigía una publicidad absoluta en toda acción de los funcionarios, para que se sintiese controlado en todo momento, y proveyendo de información sobre estos sujetos a la ciudadanía, que, en definitiva, era la que los podía responsabilizar a través de los comicios. 
Como consecuencia de la Revolución Industrial se produjo una serie de cambios demográficos y poblacionales, así como en aspectos sociales claves, debido fundamentalmente a las exigencias y a las condiciones de vida impuestas por la economía manufacturera que acababa de emerger.

Los trabajadores de las fábricas vivían en condiciones de vida paupérrimas, excesivamente precarias, hasta el punto de contarse en las factorías con mano de obra infantil para desarrollar labores peligrosas e inseguras. Igualmente, no se contaba con ninguna regulación en materia de horarios o sueldos, lo que redundaba en jornadas laborales interminables. Destacable de aquel periodo es también el aciago hacinamiento de personas en los barrios obreros, aledaños a los talleres industriales, que difícilmente gozaban de los servicios necesarios para llevar una vida digna.

Ello dio lugar al surgimiento de ciertas reivindicaciones de los obreros acerca del mejoramiento de la situación a la que se veían sometidos, para poder vivir con un mínimo de decencia, lo que se materializó en las corrientes de pensamiento del socialismo utópico, en un primer momento, y en el socialismo científico, posteriormente, con Marx y Engels como ideólogos.

Karl Marx rompió totalmente con sus antecesores, porque veía en el Estado un instrumento, la maquinaria utilizada por las clases sociales dominantes de la que servirse para someter a las clases más populares, convirtiéndolos en asalariados (Marx, 2006, p. 607). De ahí que para él, el Estado debiera desaparecer, ya que este era el aparato que posibilitaba los abusos de los detentadores del poder, desde el principio de los tiempos $^{44}$ (Vásquez Cárdenas, et al., 2011, p. 239).

\section{Otros acontecimientos de finales del siglo XIX}

Es manifiesto que el propio Abraham Lincoln, a la hora de conseguir la abolición de la esclavitud en 1865, tuvo que recurrir a acciones corruptas, como serían la práctica del soborno, el tráfico de influencias

$44 \mathrm{Y}$ es que Marx intentó explicar el crimen, en general, y la corrupción, en particular, desde un análisis económico de sus consecuencias y desde un enfoque o aproximación situado en la producción "inmaterial" (Marx, 1968, pp. 399-401). 
o, incluso, el cohecho, a efectos de asegurar la votación de la enmienda constitucional, para la cual requería del voto favorable de dos tercios de la cámara; de este modo, aun cuando teleológicamente perseguía un motivo loable, tuvo que hacer uso de prácticas sépticas (Brioschi, 2004, p. 119; Spielberg, 2012).

Igualmente, desde mediados de siglo, Otto von Bismarck comenzó su aparición pública en la política prusiana, actuando en base a la Realpolitik, ${ }^{45}$ es decir, la política basada en intereses prácticos y acciones concretas para conseguir el bien de un país en las circunstancias coetáneas, independientemente de los medios para lograrlo (Fernández Díaz, 2004, p. 59).

Para terminar, es dable destacar la respuesta ofrecida por la Iglesia católica ante un siglo de cambios sociales tan profundos. ${ }^{46}$ En este sentido, el siglo XIX concluyó con la promulgación por el papa León XIII, en 1891, de la primera Encíclica social de la historia, la Rerum Novarum, esto es, "De las cosas nuevas".

Esta carta solemne surgió como respuesta a cierto ápice de sindicalismo obrero clandestino en Estados Unidos, dirigido por católicos de buena posición, en un mundo caracterizado por la "avaricia, la opresión y la corrupción", que deterioraba la vida de los obreros, situándolos en una condición ínfima ante los abusos cometidos en sus personas (Pell, 1993, pp. 178-186).

Así, en dicha Encíclica el Sumo Pontífice trató muchos de los temas sociales preocupantes en aquel entonces en clave católica, como aspectos del socialismo o el comunismo. Igualmente, prestó atención a la propiedad privada, al papel del Estado, a algunos derechos que le competían a los trabajadores o, incluso, abordó el papel que debería protagonizar la Iglesia de aquel entonces. No obstante, la última meta que perseguía esta carta papal fue la consideración del bien común. ${ }^{47}$

45 Evolución del concepto de Maquiavelo, de Richelieu, e incluso de Sun Tzu.

46 No sólo sociales. Piénsese en la Industrialización - primera y segunda fase, esta última se inicia en torno a 1860 o 1870-, las revoluciones liberales burguesas, la independencia de las colonias, la promulgación de las primeras constituciones nacionales y de las primeras declaraciones de derechos, el auge del socialismo y nuevas ideas políticas, los procesos de reunificación estatal, y las continuas guerras, tanto civiles de los países recientemente emancipados como entre las potencias tradicionales, como es el caso de la franco-prusiana.

47 Véase el texto íntegro de la Encíclica, dado en Roma, en San Pedro, el 15 de mayo de 1891. 


\section{Conclusiones}

A finales del XVIII y durante el siglo XIX el problema de la corrupción ya era apreciado por la ciudadanía de la época; de este modo, los dirigentes y políticos de ambos lados del Atlántico intentaron controlar y poner coto a este fenómeno degenerativo, a través de la tipificación y castigo -incluso con la pena capital- de las conductas delictivas vinculadas a la corrupción en las normas e incipientes códigos legales de aquellos años.

No obstante, en muchas ocasiones, los propios dirigentes que penalizaban la corrupción hacían uso de actividades delictuales de dudosa legitimidad, como consecuencia de la observancia de los intereses propios y particulares. ${ }^{48}$

Por tanto, no es de extrañar que los teóricos y pensadores de la época hicieran alusión a la corrupción y quisieran establecer el origen de tal fenómeno.

Sin embargo, el filósofo que durante el siglo XIX presta mayor atención a la corrupción fue el utilitarista Jeremy Bentham, toda vez que intentó explicar "criminológicamente" la conducta de índole séptica y algunos elementos del actual "tipo".

Ahora bien, también imaginó ciertas medidas o herramientas que eliminarían las prácticas relativas a la corrupción pública, y que posiblemente hoy en día se podrían repensar y replantear con la finalidad de incorporarlas en nuestros ordenamientos jurídicos.

De este modo, el planteamiento benthamiano sigue la senda iniciada por los pensadores modernos y del renacimiento, y otorga a la ciudadanía un papel protagonista en el juzgamiento de la corrupción, pero esta vez desarrollado fundamentalmente a través de la confianza interferida por medio de los procedimientos electorales.

Por ello, es muy posible que tuviera razón el padre del utilitarismo y lo idóneo sería que se evaluase constantemente la labor de los gobernantes, valorando los ciudadanos la persecución de la utilidad y/o satisfacción de la mayoría en las políticas desarrolladas por el gobierno.

Ahora bien, Bentham se refirió a un control ciudadano anual, aunque posiblemente esto no sería operativo para el funcionamiento democrático.

48 Se puede reiterar a Napoleón, Bolívar o Lincoln, por mencionar algunos. 
De todas formas, ¿acaso no viene sucediendo así para el caso español en los últimos años? Parece ser que la respuesta es afirmativa, tanto a nivel nacional como a nivel autonómico, ya que ante los sucesivos casos de corrupción surgieron nuevos partidos políticos que han modificado el tradicional bipartidismo. ${ }^{49}$ Como consecuencia de ello, en los últimos años en España se han sucedido varias mociones de censura y adelantamiento de elecciones mucho antes de los estipulados cuatro años de mandato, ante la falta de acuerdos e imposible gobernabilidad del eventual presidente del Estado o de las Comunidades Autónomas.

Por tanto, parece más que probable que una buena solución contra la corrupción sería dar poder a la ciudadanía, para que se pueda valorar la labor de gobernantes y funcionarios constantemente en base a la utilidad particular -y globalmente, a los intereses universales alcanzados gracias al trabajo de estos, pudiendo remover la ciudadanía a los mismos de su puesto con la suficiente facilidad.

\section{Referencias}

Bentham, J. (1989). First Principles Preparatory to Constitutional Code. Oxford: Clarendon Press.

Bolívar, S. (2009). Doctrina del libertador. Caracas: Fundación Biblioteca Ayacucho. Brioschi, C. A. (2004). Breve storia della corruzione. Dall'età antica ai giorni nostri. Roma: TEA.

Burkhardt Pérez, I. G. (2013). De repetundis. Represión de la corrupción política en la Roma republicana. Apuntes para la reflexión frente a la futura Ley de Transparencia, Acceso a la Información Pública y Buen Gobierno. En M. C. Pérez López (coord.), Fundamenta Ivris. Terminología, principios e interpretatio. De Roma a la actualidad, (pp. 9-15). Almería, España: Editorial de la Universidad de Almería.

49 Este fenómeno ha venido sucediendo a nivel global. Piénsese en la radicalización del panorama político mundial, y el auge de partidos políticos nuevos en Europa -como Podemos y vox en España, M5s en Italia o Syriza en Grecia-. Igualmente, este fenómeno se ha trasladado a América. En este sentido, baste recordar la irrupción de Donald Trump, la irrupción de Cambiemos y Macri en Argentina -con las acusaciones de corrupción contra Cristina Fernández de Kirchner-, o más recientemente la elección de Jair Bolsonaro en Brasil tras las siglas del PSL, y las acusaciones contra Temer, Da Silva o Rousseff. 
Carpintero Benítez, F. (2011). Apuntes de filosofía del Derecho, Jerez de la Frontera: Facultad de Derecho de la Universidad de Cádiz. Recuperado de http:// franciscocarpintero.com/pdf/Libros/Apuntes\%20de\%20Filosof\%C3\%ADa\%20del\%20Derecho.pdf. [Consultado: 20/12/2018].

Coronel, G. (2006). Corruption, mismanagement, and abuse of power in Hugo Chavez's Venezuela. Development Policy Analysis (CATO Institute), 2, 1-23.

De Almeida Mendoça, A. L. (2013). Principios en materia de recuperación de activos procedentes de la corrupción. Boletín Estado de Derecho y Buen Gobierno, I(3). Recuperado de http://buengobierno.usal.es/revista/index.php.

Enríquez Pérez, I. (2008). El modelo económico de Adam Smith y el papel que le asigna a las Instituciones y al Estado en la economía. Laissez-Faire. Revista de la Facultad de Ciencias Económicas de la Universidad Nacional Autónoma de México, 28-29, 18-28. Recuperado de http://laissezfaire.ufm.edu/index.php/ Laissezfaire28_4.pdf. [Consultado: 25/12/2018].

Ferguson, N. (2009). El triunfo del dinero. Cómo las finanzas mueven el mundo. Barcelona: Debate.

Fernández Aguado, J. (2013). Egipto. Escuela de directivos. Madrid: LID.

Fernández Díaz, A. (2004). La recuperación de la ética en la economía a través de la teoría de la justicia. Discurso de investidura como Doctor Honoris Causa. Cádiz: Servicio de Publicaciones de la Universidad de Cádiz.

Flores Vega, M. E Espejel Mena, J. (2008). Corrupción y transparencia: una aproximación desde la filosofía política de Immanuel Kant. Espacios Públicos, 11(21), 44-66.

Franco, G. (1962). Las leyes de Hammurabi: versión española, introducción y anotaciones. Revista de Ciencias Sociales, 6(3), 331-356.

González, J. L. (1995). Bosquejo de historia de la Iglesia. Decatur: Asociación para la Educación Teológica Hispana.

González, J. L. (2011). Introducción a la historia de la Iglesia. Nashville: Abingdon Press.

Grande Chica, A. (2014). ¿Es la corrupción algo nuevo? ¿Es la corrupción algo malo? Revista Crítica, 989, 61-65.

Hegel, G. (1821). Grundlinien der Philosophie des Rechts (Mit Hegels eigenhändigen Randbemerkungen in seinem Handexemplar der Rechtsphilosophie), Hamburgo: F. Meiner Verlag.

Hegel, G. (1966). Fenomenología del Espíritu. México, D. F.: Fondo de Cultura Económica.

Hobbes, T. (2004). Leviatán o la materia, forma y poder de una república eclesiástica y civil. Buenos Aires: Losada. 
Kant, I. (1999). Hacia la paz perpetua. Madrid: Nueva Biblioteca.

Locke, J. (2004). Segundo ensayo sobre el gobierno civil. Buenos Aires: Losada.

Manfred, A. (1988). Napoleón Bonaparte. Torrejón de Ardoz: Akal.

Maquiavelo, N. (2004). Discursos sobre la primera década de Tito Livio. Buenos Aires: Losada.

Marx, K. (1968). Oeuvres, Tomo 2 "Matérieux pour l'Économie". París: Gallimard. Marx, K. (2006). El Capital. México, D. F.: Fondo de Cultura Económica.

Meza Ingar, C. (2002). La ley y la lucha anticorrupción: caso de las fundaciones en el Perú. Docentia et Investigatio, 4(5), 83-99.

Pell, G. (1993). Rerum Novarum: Cien años después. Estudios Públicos, 50, 177-200.

Péronnet, M. (1984). Vocabulario básico de la Revolución Francesa. Barcelona: Crítica. Rodríguez Kauth, A. (1987). Interpretación psicosocial de la corrupción política a partir de la práctica amorraladora. Arquivos Brasileiros de Psicologia, 39(4), 14-20.

Rousseau, J. J. (2005). El contrato social. Buenos Aires: Losada.

Rubio Carracedo, J. (2009). Educar ciudadanos: el planteamiento republicano-liberal de Rousseau. En J. Rubio Carracedo, J. M. Rosales E M. Toscano (eds.), Educar para la ciudadanía: perspectivas ético-críticas, Suplemento VIII, pp. 212-227. Recuperado de http://www.revistas.uma.es/index.php/contrastes/article/ view/1354/1304.

Ruiz-Morales, M. L. (2018). Corruptelas y prácticas ilícitas en la Antigüedad: soluciones análogas a las actuales en la historia del pensamiento. Foro, Nueva Época, 21(1), 303-327.

Salcedo Bastardo, J. L. (1977). Historia fundamental de Venezuela. Caracas: Fundación Gran Mariscal de Ayacucho.

Sampedro, J. L. (2002). El mercado y la globalización. Madrid: Destino.

Schofield, P. (2002). Un genio para la legislación. La perdurable atracción del pensamiento legal y político de Jeremy Bentham. Universitas Philosophica, 39, 49-78.

Sciacca, M. F. (1960). Qué es el humanismo. Buenos Aires: Columba.

Smith, A. (1794). Investigación de la naturaleza y causas de la Riqueza de las Naciones. Valladolid: Oficina de la Viuda e Hijos de Santander.

Spielberg, S. (2012). Lincoln [película]. DreamWorks. Recuperado de https:// www.youtube.com/watch?v=rG2vCfBxLro. [Consulta: 30/12/2018].

Téllez Alarcia, D. (2001). La independencia de los EE.UU. en el marco de la "Guerra Colonial" del S. XVIII (1739-1783). Tiempos Modernos, 2(5), 1-35. Recuperado de http://www.tiemposmodernos.org/tm3/index.php/tm/ issue/view/5.

Tocqueville, A. (1957). La democracia en América. México D. F.: Fondo de Cultura Económica. 
Vacas García-Alós, L. (2012). La influencia de la Constitución de 1812 en el control de las cuentas públicas. Revista de Derecho Político, 83, 382-396.

Vásquez Cárdenas, A. V. \& Montoya Brand, M. (2011). Corrupción, lucha anticorrupción y formas de gobierno: hacia la búsqueda del concepto de corrupción. Estudios de Derecho, LXVIII(152), 229-253.

Zavala Treviño, J. R. (2013). Apuntes sobre la historia de la corrupción. Monterrey: Universidad Autónoma de Nuevo León.

Zingarelli, A. P. (2016). Tebas durante el periodo Ramésida: redistribución y circulación de bienes. Revista Mundo Antigo, 9, 53-66. 